\title{
Risk of non-melanoma skin cancer in patients with psoriasis: An updated evidence from systematic review with meta-analysis
}

\author{
Xiujuan Wang $1^{*}$, Qiang $\operatorname{Liu}^{2,} 3^{* 凶}$, Lingling $\mathrm{Wu}^{1}$, Zhenhua Nie ${ }^{1}$, Zubing Mei ${ }^{4,5 凶}$ \\ 1. Department of Dermatology, Tianjin Academy of Traditional Chinese Medicine Affiliated Hospital, Tianjin, People's Republic of China. \\ 2. Department of Medical Acupuncture, The First Affiliated Hospital of Tianjin University of Traditional Chinese Medicine, Tianjin, People's Republic of \\ China. \\ 3. National Clinical Research Center for Traditional Chinese Medicine, Tianjin, People's Republic of China. \\ 4. Department of Anorectal Surgery, Shuguang Hospital, Shanghai University of Traditional Chinese Medicine, Shanghai, China \\ 5. Anorectal Disease Institute of Shuguang Hospital, Shanghai, China. \\ * These authors contributed equally as co-first authors.
}

$\square$ Corresponding author: Dr. Qiang Liu, Department of Medical Acupuncture, The First Affiliated Hospital of Tianjin University of Traditional Chinese Medicine, National Clinical Research Center for Traditional Chinese Medicine, 314 Anshan West Road, Nankai District, Tianjin, 300193, People's Republic of China, Tel: 86-15900335536 E-mail: 15900335536@163.com; Dr. Zubing Mei, Department of Anorectal Surgery, Shuguang Hospital, Shanghai University of Traditional Chinese Medicine, 528 Zhangheng Road, Shanghai 201203, People's Republic of China. Tel: 86-2120256187 E-mail: herrmayor@shutcm.edu.cn or herrmayor@126.com

(c) The author(s). This is an open access article distributed under the terms of the Creative Commons Attribution License (https://creativecommons.org/licenses/by/4.0/). See http://ivyspring.com/terms for full terms and conditions.

Received: 2019.05.26; Accepted: 2019.10.20; Published: 2020.01.01

\begin{abstract}
Background Psoriasis is a chronic inflammatory skin disorder which may result in an increased cancer risk due to defects of immune surveillance. The relationship between psoriasis and risk of non-melanoma skin cancer (NMSC) has not yet been fully determined. The aim of this study was to update the evidence on the association between psoriasis and risk of NMSC.

Methods We conducted an extensive literature search of publications in Pubmed, EMBASE, and Cochrane Library without restrictions on language from inception through August 2019 using predefined keywords. Eligible observational studies were selected if they assessed the risk ratio of NMSC in patients with psoriasis. Data from included studies were extracted, and meta-analysis was performed using random-effects models.

Results Sixteen cohort studies involving 16,023,503 participants published between 1999 and 2019 met inclusion criteria and were included in this systematic review. Meta-analysis demonstrated that compared with patients without psoriasis, patients with psoriasis had 1.72 times higher risk of developing NMSC (RR, 1.72, 95\% Cl 1.46 to 2.02). Patients with moderate to severe psoriasis had higher risk of NMSC (RR, 1.82, 95\% Cl 1.38 to 2.41$)$ than those had mild psoriasis (RR, $1.61,95 \% \mathrm{Cl}$ 1.25 to 2.09 ) ( $P$ for interaction $<0.001$ ). Moreover, patients with psoriasis had significantly higher risk of squamous cell carcinoma (RR, $2.08,95 \% \mathrm{Cl} 1.53$ to 2.83 ) than that of basal cell carcinoma (RR, $1.28,95 \% \mathrm{Cl} 0.81$ to 2.00 ) ( $\mathrm{P}$ for interaction<0.001).

Conclusions Current evidence suggests that patients with psoriasis may have a higher risk of NMSC than psoriasis-free patients. Periodic screening for specific cancer risk is warranted in patients with psoriasis.
\end{abstract}

Key words: Non-melanoma skin cancer (NMSC); Psoriasis; Risk ratio; observational study; Meta-analysis.

\section{Introduction}

Psoriasis is a chronic inflammatory and immune disease that affects more than $2-3 \%$ of the world's general population. ${ }^{1,2}$ Psoriasis mainly damages skin with the main pathological features of excessive 
growth and differentiation of keratinocytes. It has been reported that the immune cells, especially $\mathrm{T}$ cells were involved in the immune response, which has a major impact on the pathogenesis of psoriasis. ${ }^{3}$ Studies also show that psoriasis shares several clinical features with other chronic illness including psoriatic arthritis, metabolic syndrome, depression, cardiovascular diseases and even malignancies. 4-6

Due to the exposure to immunosuppressive agents, methotrexate, cyclosporine, and UV therapies, there seems to be increased cancer risk in patients with psoriasis.7, 8 However, the association between psoriasis and the risk of non-melanoma skin cancer (NMSC) is still controversial. Several epidemiological studies have demonstrated an increased risk of skin cancers in Caucasian patients with psoriasis who had psoralen plus ultraviolet A (PUVA) therapy. ${ }^{9-12}$ However, several other cohorts found the opposite results. ${ }^{13,} 14$ Thus, it is currently uncertain whether psoriasis is associated with elevated risk of NMSC. Given the accumulating epidemiological evidence associated with patients with psoriasis, it is considered clinically important to gain a better understanding if psoriasis condition really affects NMSC risk.

We therefore performed a systematic review and meta-analysis of observational studies investigating the association between psoriasis status and risk of NMSC. The primary aim of this systematic review and meta-analysis was to precisely gauge the nature and magnitude of this association in patients with psoriasis. We also assessed whether the severity of psoriasis can have an impact on the development of NMSC and whether psoriasis status can affect different pathologic type of NMSC.

\section{Methods}

\section{Literature search}

A systematic review was performed based on the Preferred Reporting Items for Systematic Reviews and Meta-Analyses (PRISMA) guidelines. ${ }^{15}$ We also followed the Meta-analysis Of Observational Studies in Epidemiology (MOOSE) guidelines for the meta-analysis of these studies, ${ }^{16}$ in that we involved observational studies.

We conducted an extensive literature search of publications in Pubmed, EMBASE, and Cochrane Library without restrictions on language from inception through August 2019 for identifying observational studies examining the association between psoriasis and risk of NMSC. The search free text terms were "psoriasis" AND ("skin neoplasms" OR "non-melanoma skin cancer" OR "NMSC" OR "keratinocyte carcinoma" OR "basal cell carcinoma"
OR "squamous cell carcinoma"). MeSH (Medical Subject Headings) terms were also searched (Supplementary Search Strategy). We did not apply language restrictions. In addition, manual search of potentially additional citations within references of the included studies, reviews and meta-analyses was also carried out for locating additional suitable studies not found by the electronic database searches. A search for unpublished literature was not applied.

\section{Study selection}

The study inclusion criteria included (i) being population-based or hospital-based prospective or retrospective study with cohort, case-cohort or nested case-control design; report adjusted estimates of the relative risk (RR) [e.g. hazard ratio (HR), risk ratio or odds ratio (OR)] with corresponding 95\% confidence intervals (CIs) for the association of psoriasis and NMSC risk. When the same cohort published more than one article on psoriasis and NMSC risk, the most comprehensive one with the largest sample size was selected.

\section{Data extraction and quality assessment}

Two reviewers (XW and QL) independently selected studies that potentially satisfied the inclusion criteria based on their titles or/and abstracts. If necessary, we would retrieve the full text articles for a more detailed assessment and eligibility for inclusion. For each included study, two reviewers (XW and QL) independently extracted related data including first author, year of publication, study country and design, study setting, cohort sample size, percent of female, measure of psoriasis, outcome ascertainment, mean/median follow-up period, adjusted covariates, and OR, HR, RR, SIR along with their associated 95\% CIs. The results of the abstracted data were cross-checked. Any disagreements were resolved by discussion or contacted a senior reviewer (ZM).

The Newcastle-Ottawa scale (NOS) was used to assess study quality for observational study. This scale, ranging from 0 to 9 scores assigned for participant selection, comparability and outcome (cohort) or exposure ascertainment (case-control), and the potential for confounding. ${ }^{17}$ We defined a total NOS score being 7 or more as high quality study $^{49}$ and a score being less than 7 as low quality study.

\section{Statistical analysis}

Data analysis was undertaken using Stata ${ }^{\circledR}$ version 13.0 (Stata Corp LP, College Station, Texas, USA). A random-effects meta-analysis was performed to calculate the summary RRs and the $95 \%$ CIs, using the approach described by DerSimonian and Laird et.al. ${ }^{18}$ Inter-study heterogeneity was examined using 
$\mathrm{I}^{2}$ statistic defining the percentage of the total variation across studies, with an $\mathrm{I}^{2}$ more than $50 \%$ representing significant heterogeneity. ${ }^{19}$ To examine the potential sources of heterogeneity, subgroup analyses were conducted by geographic continent, study setting, sex, sample size, follow-up period, study quality, adjustment for major variables, psoriasis severity and pathologic type. Besides, visual inspection of funnel plot asymmetry combined with Egger's regression ${ }^{20}$ and Begg's rank correlation tests ${ }^{21}$ was used to test publication bias with a $\mathrm{P}<0.05$ indicating the presence of publication bias. Finally, trim-and-fill approach was also applied to explore the potential influence of publication bias by calculating the number of missing studies that might exist in a meta-analysis. ${ }^{22}$ A cumulative meta-analysis by sorting of the included studies was also conducted based on the date of study publication.

\section{Results}

\section{Literature Search and Study characteristics}

Figure 1 demonstrates the flow diagram for literature selection and inclusion in this meta-analysis, which generated 7759 records. Thirty-six potentially relevant citations were then identified for full text review. Finally, a total of 16 cohort studies involving
16,023,503 participants published between 1999 and 2019 met the inclusion criteria and were included in the final analysis. ${ }^{13,} 23-35,50,51$ The median sample size was 173,170 (range, 5687 to 5559420). The median follow-up period ranged from 1 to 16 years. We presented the summary descriptions of each included study in Table 1. In summary, all studies were published between 1999 and 2019, with 11 studies involved population-based cohorts, and 5 had hospital-based cohorts. Six of the studies examined populations from North America, seven studies were from European countries and three investigated Asian populations. Eight studies used regression model adjusted for major variables such as sex, age and body mass index. In terms of method for ascertainment of psoriasis and NMSC, most of the studies used a diagnosis based on International Classification of Diseases (ICD) criteria collected in the database.

\section{Meta-analysis}

As shown in Figure 2, the summarized data from the included 16 studies indicated that compared with patients without psoriasis, patients with psoriasis had 1.72 times higher risk of developing NMSC (RR, 1.72, 95\% CI 1.46 to 2.02 ), with significant heterogeneity across studies $\left(\mathrm{I}^{2}=96.8 \%\right)$.

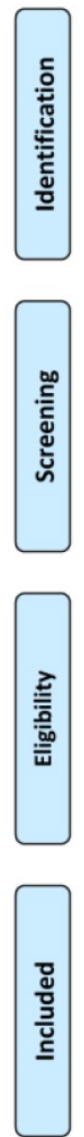

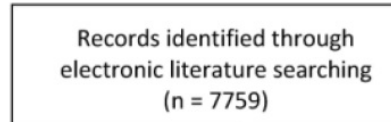
$n=7759$
Additional records identified through additional sources $(n=0)$
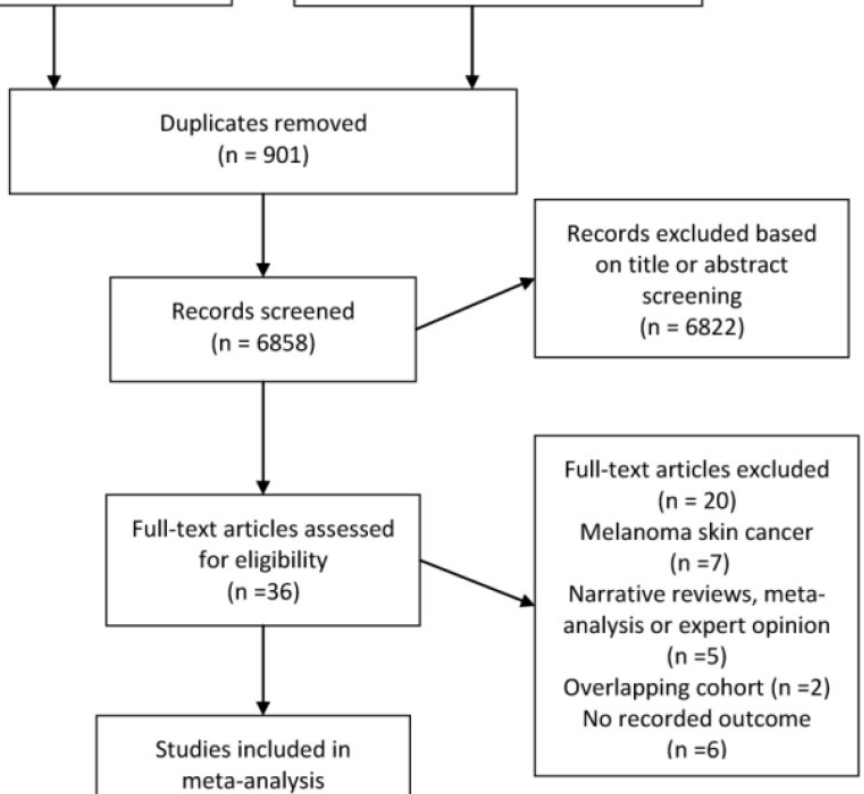

meta-analysis

$(\mathrm{n}=16)$ 
Table 1. Summary characteristics of included studies.

\begin{tabular}{|c|c|c|c|c|c|c|c|c|c|c|}
\hline Author (year) & Country & Study design & Study setting & $\begin{array}{l}\text { Cohort } \\
\text { sample } \\
\text { size }\end{array}$ & $\begin{array}{l}\text { Female } \\
(\%)\end{array}$ & $\begin{array}{l}\text { Measure of } \\
\text { Psoriasis }\end{array}$ & $\begin{array}{l}\text { Outcome } \\
\text { ascertainment }\end{array}$ & $\begin{array}{l}\text { NOS } \\
\text { score }\end{array}$ & $\begin{array}{l}\text { Mean/median } \\
\text { follow-up } \\
\text { period }\end{array}$ & Adjusted covariates \\
\hline Lee (2019) & Korea & $\begin{array}{l}\text { Prospective } \\
\text { cohort }\end{array}$ & Population-based & $1,775,068$ & 38.4 & ICD-10 & $\begin{array}{l}\text { The national cancer } \\
\text { registry or hospital } \\
\text { admission report }\end{array}$ & 8 & 15 years & $\begin{array}{l}\text { Age, sex, smoking status, } \\
\text { alcohol consumption, exercise, } \\
\text { body mass index, } \\
\text { hypertension and diabetes }\end{array}$ \\
\hline Lee (2018) & Korea & $\begin{array}{l}\text { Prospective } \\
\text { cohort }\end{array}$ & Population-based & 5352534 & 48.3 & ICD-10 & ICD-10 & 8 & 8 years & $\begin{array}{l}\text { Diabetes, hypertension, } \\
\text { dyslipidemia, income level } \\
\text { and place of residence }\end{array}$ \\
\hline $\begin{array}{l}\text { Kimball } \\
(2018)\end{array}$ & USA & $\begin{array}{l}\text { Retrospectiv } \\
\text { e cohort }\end{array}$ & Population-based & 358132 & 51.7 & ICD-9 & ICD-9 & 8 & 12 months & NR \\
\hline Gu (2017) & USA & $\begin{array}{l}\text { Retrospectiv } \\
\text { e cohort }\end{array}$ & Population-based & 86251 & 61.2 & ICD-9 & ICD-9 & 5 & 18.6 months & NR \\
\hline Didona (2017) & Italy & $\begin{array}{l}\text { Retrospectiv } \\
\text { e cohort }\end{array}$ & Hospital-based & 98695 & 53.6 & ICD-9 & ICD-9 & 4 & NR & $\begin{array}{l}\text { Gender, age, phototherapy } \\
\text { yielded }\end{array}$ \\
\hline Asgari (2017) & USA & $\begin{array}{l}\text { Retrospectiv } \\
\text { e cohort }\end{array}$ & Population-based & 5889 & 49 & ICD-9 & ICD-9 & 7 & 5.86 years & $\begin{array}{l}\text { Presence of psoriatic arthritis, } \\
\text { prior ultraviolet light therapy, } \\
\text { body mass index, and cigarette } \\
\text { use. }\end{array}$ \\
\hline $\begin{array}{l}\text { Egeberg } \\
(2016)\end{array}$ & $\begin{array}{l}\text { Denmar } \\
\mathrm{k}\end{array}$ & $\begin{array}{l}\text { Retrospectiv } \\
\text { e cohort }\end{array}$ & Population-based & 5559420 & 50.6 & $\begin{array}{l}\text { ICD-8 } \\
\text { code } 173 \\
\text { or ICD-10 } \\
\text { code C44 }\end{array}$ & $\begin{array}{l}\text { ICD- } 8 \text { code } 173 \text { or } \\
\text { ICD-10 code } C 44\end{array}$ & 7 & 16 years & NR \\
\hline Dai (2016) & USA & $\begin{array}{l}\text { Retrospectiv } \\
\text { e cohort }\end{array}$ & Population-based & 157934 & 100 & $\begin{array}{l}\text { Psoriasis } \\
\text { Screening } \\
\text { Tool }\end{array}$ & $\begin{array}{l}\text { Psoriasis Screening } \\
\text { Tool }\end{array}$ & 7 & 16 years & $\begin{array}{l}\text { Age, BMI, exercise, alcohol } \\
\text { intake, smoking, family history } \\
\text { of melanoma, nevi counts on } \\
\text { extremity, } \\
\text { susceptibility to burn, hair } \\
\text { color, number of severe or } \\
\text { blistering sunburns, and } \\
\text { ultraviolet index at birth. }\end{array}$ \\
\hline Chiesa (2016) & UK & $\begin{array}{l}\text { Retrospectiv } \\
\text { e cohort }\end{array}$ & Population-based & 1136082 & 55.2 & Read code & Read code & 8 & 5 years & $\begin{array}{l}\text { Age, sex, BMI, drinking and } \\
\text { smoking status }\end{array}$ \\
\hline Chen (2013) & USA & $\begin{array}{l}\text { Mixed } \\
\text { retrospective } \\
\text { - prospective } \\
\text { cohort }\end{array}$ & Population-based & 188406 & NR & NR & NR & 1 & NR & NR \\
\hline Lee (2012) & China & $\begin{array}{l}\text { Retrospectiv } \\
\text { e cohort }\end{array}$ & Population-based & 1007061 & 50.4 & ICD-9 & ICD-9 & 7 & 4.8 years & Age and sex \\
\hline Ji (2009) & Sweden & $\begin{array}{l}\text { Retrospectiv } \\
\text { e cohort }\end{array}$ & Hospital-based & 15858 & NR & $\begin{array}{l}\text { ICD-7,8,9,1 } \\
0\end{array}$ & ICD-7 & 6 & 10 years & NR \\
\hline $\begin{array}{l}\text { Margolis } \\
(2001)\end{array}$ & USA & $\begin{array}{l}\text { Retrospectiv } \\
\text { e cohort }\end{array}$ & Hospital-based & 259808 & NR & $\begin{array}{l}\text { ICD-9-CM } \\
\text { codes }\end{array}$ & ICD-9-CM codes & 6 & 2.27 years & Age, sex and state of residence \\
\hline Boffetta (2001) & Sweden & $\begin{array}{l}\text { Retrospectiv } \\
\text { e cohort }\end{array}$ & Population-based & 9773 & 45.7 & ICD-7,8,9 & ICD-7 & 6 & 10.6 years & NR \\
\hline $\begin{array}{l}\text { Hannuksela-S } \\
\text { vahn (2000) }\end{array}$ & Finnish & $\begin{array}{l}\text { Retrospectiv } \\
\text { e cohort }\end{array}$ & Hospital-based & 5687 & 44.9 & $\begin{array}{l}\text { The } \\
\text { personal } \\
\text { identificati } \\
\text { on codes }\end{array}$ & ICD-9 & 5 & 14 years & NR \\
\hline Frentz (1999) & Danish & $\begin{array}{l}\text { Retrospectiv } \\
\text { e cohort }\end{array}$ & Hospital-based & 6905 & 50.5 & $\begin{array}{l}\text { The } \\
\text { personal } \\
\text { identificati } \\
\text { on codes }\end{array}$ & ICD-0 & 6 & 9.3 years & NR \\
\hline
\end{tabular}

Abbreviations: BMI, body mass index; ICD, International Classification of Diseases; NOS, Newcastle-Ottawa Scale; NR, not reported.

Table 2 gives the results of detailed subgroup analyses by potential sources of heterogeneity among some of the major clinical features of the included studies. The pooled RRs for the majority of subgroups remained constant by the study features, including geographic continent, study setting, sample size, follow-up period, adjusted variables, study quality, and psoriasis severity. A possible interaction was noted in four features (geographic continent, follow-up period, psoriasis severity and pathologic type), although we had conducted multiple hypothesis testing by nine features. Though we did not observe significant associations between psoriasis and risk of NMSC for male patients (RR, 1.99, 95\% CI 0.73 to 5.43 ) or for basal cell carcinoma (RR, 1.28 , 95\%
CI 0.81 to 2.00), these associations should be further examined due to the small number of studies in each of the subgroup.

\section{Study quality, publication bias and sensitivity analysis}

The methodological quality score of the included studies was moderate to high in $88 \%(14 / 16)$ of the included studies based on the NOS score (Supplementary Table 1); most studies used population-representative subjects, had clearly reported the ascertainment of exposure, adequate length of follow-up, had a sufficient measurement of outcomes, and only one study with abstract form (27) rated low quality for lack of information. However, 
subgroup analysis based on the study quality yielded similar results between high quality studies (RR, 1.56, 95\% CI 1.28 to 1.91) and low to moderate studies(RR, $1.99,95 \% \mathrm{CI} 1.39$ to 2.84$)(\mathrm{P}=0.805)$. We also conducted sensitivity analysis by omitting the low quality study and recalculating the others, which did not alter the result largely.

Publication bias analysis indicated a little asymmetry of the funnel plot. However, Begg's rank correlation test $(\mathrm{P}=0.398)$ or Egger's test $(\mathrm{P}=0.324)$ did not suggest the asymmetry was attributed to publication bias. Thus, we used the Duval's nonparametric trim-and-fill method to adjust the pooled RR, and the result was the same with that of the primary analysis, showing the robustness of the result (Figure 3).

Sensitivity analyses were performed by omitting one study at a time and repeating the meta-analysis, showing that the omission of any study does not have a significantly influence on the overall effect (Figure 4). We also conducted a further cumulative meta-analysis by calculating the cumulative evidence at the time of each study, which showed that the effect estimates had been consistent over time, providing an indication of the robustness of the results when adding new evidence (Figure 5).
Table 2. Subgroup analyses for association between psoriasis and risk of non-melanoma skin cancer.

\begin{tabular}{|c|c|c|c|c|c|}
\hline Subgroup & $\mathrm{RR}$ & $95 \%$ CI & $\begin{array}{l}\mathrm{I}^{2} \\
(\%)\end{array}$ & $\begin{array}{l}\text { No. } \\
\text { studies }\end{array}$ & $\begin{array}{l}P \text { for } \\
\text { interaction }\end{array}$ \\
\hline Total & 1.72 & 1.46 to 2.02 & 96.8 & 316 & - \\
\hline Geographic continent & & & & & $<0.001$ \\
\hline North America & 1.61 & 1.24 to 2.10 & 94.5 & 56 & \\
\hline Europe & 1.70 & 1.33 to 2.16 & 97.3 & 37 & \\
\hline Asia & 2.01 & 0.72 to 5.61 & 95.3 & 33 & \\
\hline Study setting & & & & & 0.204 \\
\hline Population-based & 1.63 & 1.37 to 1.95 & 96.7 & 711 & \\
\hline Hospital-based & 2.01 & 1.14 to 3.53 & 97.8 & 35 & \\
\hline Sample size & & & & & 0.239 \\
\hline$<100,000$ & 1.98 & 1.23 to 3.17 & 96.7 & 77 & \\
\hline$\geq 100,000$ & 1.64 & 1.36 to 1.97 & 97.1 & 19 & \\
\hline Follow-up period (Mean/median) & & & & & $<0.001$ \\
\hline$<5$ years & 3.38 & 2.13 to 5.36 & 93.7 & 74 & \\
\hline$\geq 5$ years & 1.61 & 1.33 to 1.94 & 94.8 & 310 & \\
\hline Adjustment for major variables & & & & & $<0.001$ \\
\hline Yes & 1.63 & 1.26 to 2.12 & 95.3 & 38 & \\
\hline No/not reported & 1.79 & 1.52 to 2.11 & 93.2 & 28 & \\
\hline Gender & & & & & 0.828 \\
\hline Male & 1.99 & 0.73 to 5.43 & 67.4 & +3 & \\
\hline Female & 1.29 & 1.07 to 1.55 & 0 & 2 & \\
\hline NOS score & & & & & 0.801 \\
\hline High $(\geq 7)$ & 1.56 & 1.28 to 1.91 & 97.2 & 28 & \\
\hline Low to moderate $(<7)$ & 1.99 & 1.39 to 2.84 & 96.6 & 58 & \\
\hline Psoriasis severity & & & & & $<0.001$ \\
\hline Mild & 1.61 & 1.25 to 2.09 & 96.5 & 57 & \\
\hline Moderate to severe & 1.82 & 1.38 to 2.41 & 82.7 & 78 & \\
\hline Psoriatic arthritis & 1.62 & 1.27 to 2.05 & - & 1 & \\
\hline Pathologic type & & & & & $<0.001$ \\
\hline Basal cell carcinoma & 1.28 & 0.81 to 2.00 & 95.8 & 34 & \\
\hline Squamous cell carcinoma & 2.08 & 1.53 to 2.83 & 85.9 & 6 & \\
\hline
\end{tabular}

Figure 2. Forest plot for association between psoriasis and risk of non-melanoma skin cancer.

$\operatorname{RR}(95 \% \mathrm{Cl})$

$1.33(0.66,2.67)$
$1.25(1.02,1.55)$
$1.21(0.54,2.70)$
$1.88(1.80,1.96)$
$23.17(0.10,93.31)$
$0.84(0.75,0.95)$
$1.42(1.12,1.80)$
$1.67(1.55,1.81)$
$1.32(1.10,1.59)$
$1.62(1.27,2.05)$
$1.51(1.11,2.05)$
$0.95(0.75,1.18)$
$1.12(1.07,1.16)$
$1.40(1.09,1.79)$
$1.00(0.88,1.13)$
$7.50(5.07,11.10)$
$2.08(1.67,2.55)$
$4.15(2.52,6.84)$
$2.35(1.96,2.82)$
$2.46(1.82,3.27)$
$3.20(2.30,4.40)$
$2.46(2.13,2.83)$
$1.72(1.46,2.02)$

3




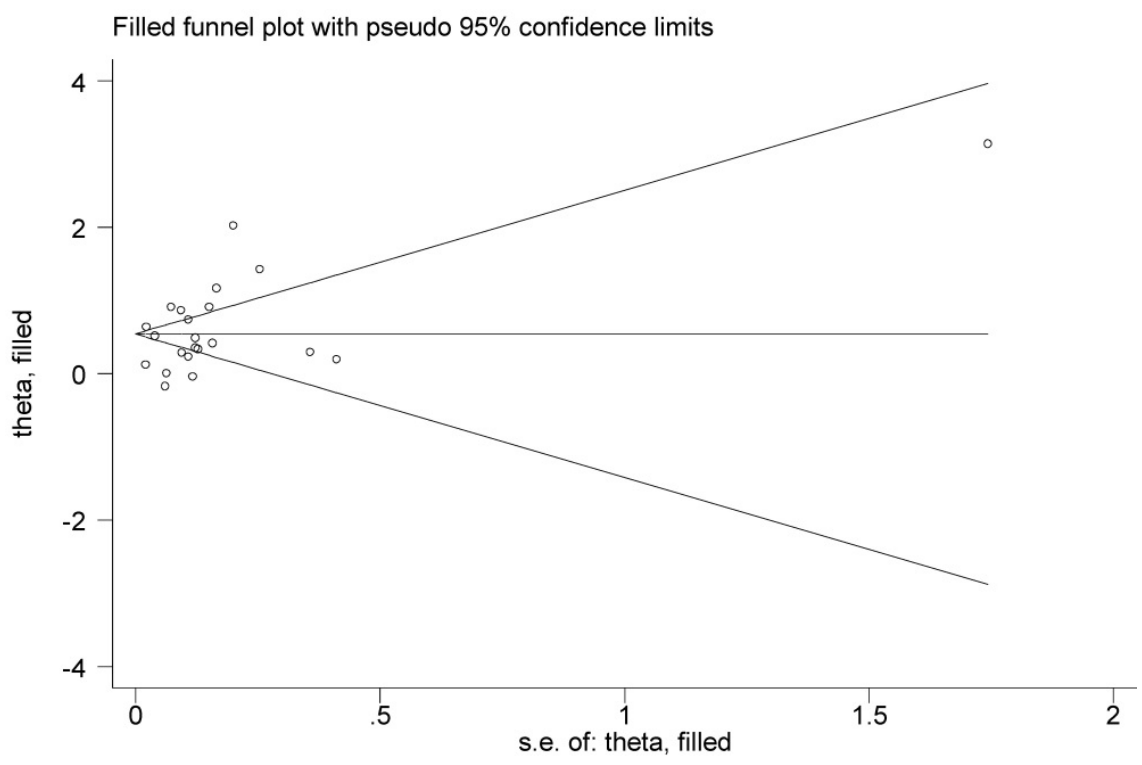

Figure 3. Filled funnel plot for association between psoriasis and risk of non-melanoma skin cancer.

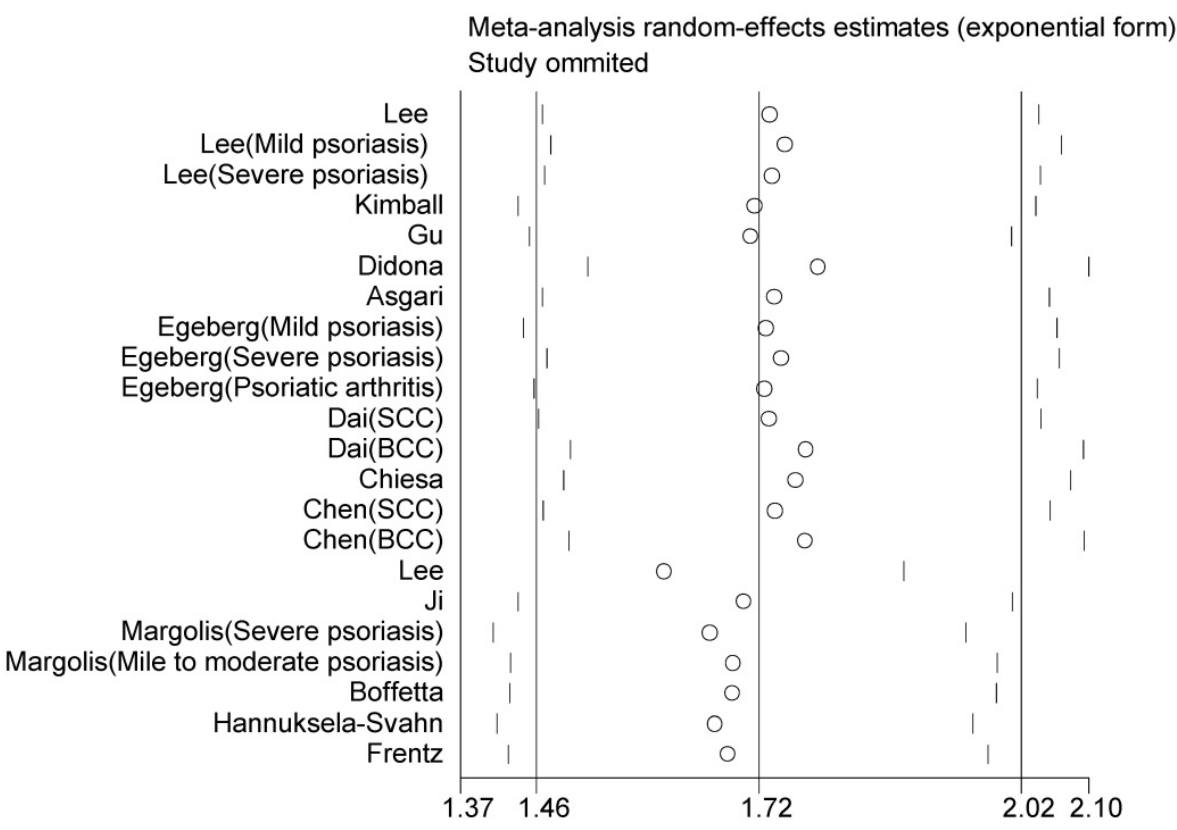

Figure 4. Sensitivity analysis by omitting individual study at one time on the summary relative risk.

\section{Discussion}

\section{Principal Findings}

Current meta-analysis of 16 cohort studies involving over $16,023,503$ participants yielded solid evidence that patients with psoriasis could have a higher risk of NMSC than psoriasis-free patients. When stratified by geographic continent, study setting, sex, sample size, follow-up period, study quality, adjustment for major variables, psoriasis severity and pathologic type, the results generally remained constant although there was significant inter-study heterogeneity underlying the pooled results.
Because several common risk factors, such as cigarette smoking, alcohol consumption, obesity, diabetes, and stressful life events, $41-44$ have been shown to be shared in patients with psoriasis and cancer, it has been proposed that patients with psoriasis tend to have higher risk of suffering from various diseases, including cancers. Nevertheless, some other studies are also proposed that patients with psoriasis may have a lower risk of cancer. ${ }^{45}$ Early hypothesis indicated that psoriasis was a protective factor for skin cancer incidence due to a reduced capacity of psoriatic skin to metabolise precarcinogens caused by impaired arylhydrocarbon hydroxylase $(\mathrm{AHH})$ activity. ${ }^{46}$ 


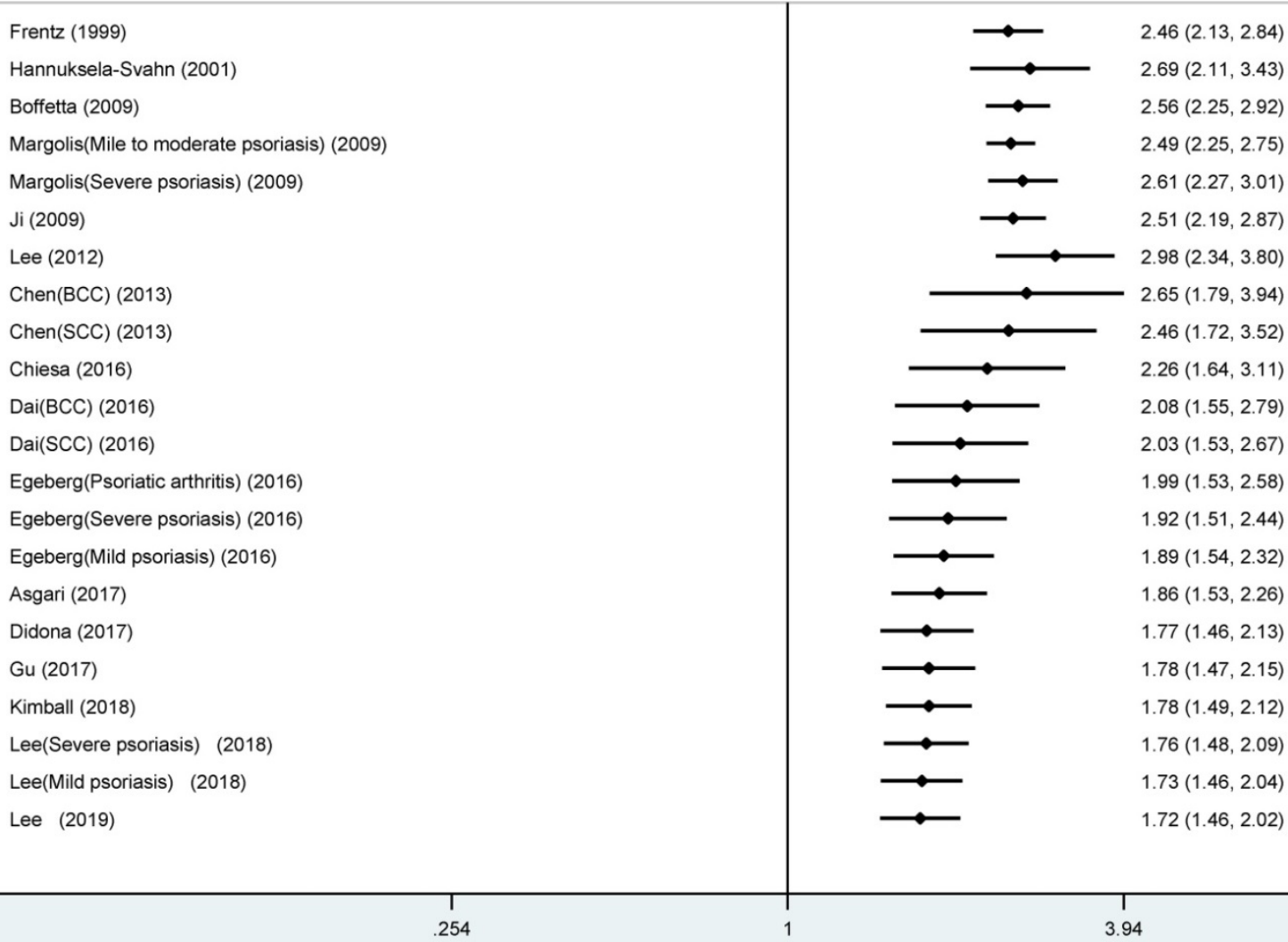

Figure 5. Cumulative influence of study on meta-analysis of association between psoriasis and risk of non-melanoma skin cancer.

Previous systematic reviews or meta-analyses have reported the association between psoriasis and the risk of NMSC, which yielded similar findings with the current one. Pouplard et al. summarized 9 studies and showed that patients with psoriasis had an increased risk of NMSC, both for squamous cell carcinoma (RR 5.31, 95\% CI 2.63 to 10.71) and basal cell carcinoma (RR 2.00, 95\% CI 1.83 to 2.20 ). ${ }^{47}$ The data by Peleva et al. also suggested that an increased risk of NMSC, particularly squamous cell carcinoma, was reported in patients with psoriasis. ${ }^{48}$ In this updated meta-analysis, we found that psoriasis was also significantly associated with risk of NMSC, but only for squamous cell carcinoma, not for basal cell carcinoma. These findings appeared to be mainly related to the exposure to PUVA treatments, which had reported to have the potential to induce p53 mutations and contribute to development of NMSC in psoriasis patients. ${ }^{13}$

\section{Strengths and Limitations}

The strengths of this updated meta-analysis were presented as follows. First, we thoroughly searched the three major databases without language or publication date limits by applying comprehensive search strategies, making the risk of missing publications less possible. Second, we made rigorously literature screening and eligibility criteria and transparently reported the findings which may minimize the possibility of publication bias. Third, to the best of our knowledge, this meta-analysis included the biggest cohort and most comprehensive analysis with more than 16,023,000 individuals regarding this topic, providing the solidest evidence for the association between psoriasis and risk of NMSC. Fourth, various stratified analyses were performed according to some influential study variables covering the study design, participant characteristics, follow-up period, study quality, exposure and outcome features. The findings were generally in line with the result of the main analysis. Another important strength of our meta-analysis that we should address was that we used a conservative method to combine the risk estimates by using the random effects model. In consequence, the main analysis yielded a considerably high inter-study variance with a prediction interval ranging from 0.81 to 3.89 , which indicated that the incidence of NMSC varied considerably in future studies comparing patients with psoriasis to psoriasis-free population. Therefore, considering the variable level of bias from the included observational studies, the significant 
heterogeneity of the meta-analysis along with the wide prediction interval, the findings of this study from observational studies may cast a shadow upon an uncertainty of the current understanding between psoriasis and risk of NMSC, though significant risk estimate was obtained from the main analysis. From this perspective, our findings of this meta-analysis underline the limitation of observational studies on association of psoriasis with NMSC risk due to a considerable inter-study heterogeneity. We consider that with further advanced methodologies in epidemiological research and RCTs, the potential effects of psoriasis with NMSC risk could be better clarified and stratified based on specific biological or pathophysiologic levels, in which aspects that future studies are warranted.

There are limitations to our study. First, the $I^{2}$ statistic was indicated that considerable inter-study heterogeneity was observed in the meta-analysis, as was expectable since great variations do exist among studies in terms of study design (prospective and retrospective), enrolled subjects, treatment strategy, follow-up period, outcomes combined with some other study features-such heterogeneity could explain partly differences in risk estimates and the associations. Furthermore, we failed to account for exposure and dose of immunosuppressive medications and latent periods for skin cancer due to insufficient data from the original articles included. Second, though some of the original studies have adjusted some major risk factors (age and gender), analysis of association between psoriasis and NMSC risks could have confounded findings. Moreover, these confounding factors remain, including body mass index drinking, smoking status and treatment, and may affect the association of psoriasis with NMSC risk. Therefore, it is strongly suggested that further studies provide detailed individual data regarding the prevalence of associated risk factors in patients with psoriasis and control subjects. Moreover, our study showed a significant variation in terms of measurement of psoriasis and outcome ascertainment among the included studies, such as different diagnostic criteria used for psoriasis and NMSC, different psoriasis treatment regimens and different methodologies to confirm NMSC diagnosis, which should all be uniformed in future studies. Additionally, only three major databases were searched without including others, enhancing the possibilities of some missing studies, though those three databases covered most of available literature. In addition, one conference abstract was included that was not peer reviewed which may lead to potential risk of bias. Finally, grey literature with unpublished data was not searched and we did not contact corresponding authors for the missing original data, which could have led to potential publication bias because studies with positive results might be published more easily than those with negative findings. Though we conducted publication bias analysis by visual inspection of the funnel plot, Egger's regression and Begg's rank correlation tests, no suspicion of small-study effects was indicated. However, we should still interpret the findings with caution.

In summary, the up-to-date evidence from observational studies indicates some extent of association between psoriasis diagnosis and NMSC risk. Due to the large heterogeneity of previously published cohort studies, we propose that in the future, further large prospective cohorts are advocated to validate the association between psoriasis and NMSC risk. Nevertheless, periodic screening for specific cancer risk is warranted in patients with psoriasis.

\section{Abbreviations}

CI: confidence interval; HR: hazard ratio; ICD: International Classification of Diseases; MeSH: Medical Subject Headings; MOOSE: the Meta-analysis Of Observational Studies in Epidemiology; NMSC: non-melanoma skin cancer; NOS: the NewcastleOttawa scale; OR: odds ratio; PRISMA: the Preferred Reporting Items for Systematic Reviews and Meta-Analyses; PUVA: psoralen plus ultraviolet A; SIR: standardized incidence ratio.

\section{Supplementary Material}

Supplementary Search Strategy and tables. http://www.jcancer.org/v11p1047s1.pdf

\section{Acknowledgements}

This work was supported by the National Natural Science Foundation of China (grant no. 81774112).

\section{Funding sources}

This work was supported by Research Project of Tianjin Health \& Family Planning Commission, Traditional Chinese Medicine \& Integration of Chinese Medicine and Western Medicine (grant no. 2017029), the National Natural Science Foundation of China (grant no. 81774112). The funders had no role in study design, data collection and analysis, decision to publish, or preparation of the manuscript.

\section{Author contributions}

Study concept and design (XW ZM); Acquisition of data (XW QL); Analysis and interpretation of data (XW QL LW); Drafting of the manuscript (QL); 
Critical revision of the manuscript for important intellectual content (all authors); Study supervision (QL ZM).

\section{Competing Interests}

The authors have declared that no competing interest exists.

\section{References}

1. Helmick CG, Lee-Han H, Hirsch SC, et al. Prevalence of psoriasis among adults in the US: 2003-2006 and 2009-2010 National Health and Nutrition Examination Surveys. American journal of preventive medicine 2014,47:37-45.

2. Parisi R, Symmons DP, Griffiths CE, et al. Global epidemiology of psoriasis: a systematic review of incidence and prevalence. Journal of Investigative Dermatology 2013,133:377-385.

3. Nestle Frank O, Kaplan Daniel H, Barker Jonathan. Psoriasis. N. Engl. J. Med., 2009, 361: 496-509.

4. Ni C, Chiu MW. Psoriasis and comorbidities: links and risks. Clinical, cosmetic and investigational dermatology 2014,7:119.

5. Dubreuil M, Rho YH, Man A, et al. Diabetes incidence in psoriatic arthritis, psoriasis and rheumatoid arthritis: a UK population-based cohort study. Rheumatology 2013,53:346-352.

6. Horreau C, Pouplard C, Brenaut E, et al. Cardiovascular morbidity and mortality in psoriasis and psoriatic arthritis: a systematic literature review. Journal of the European Academy of Dermatology and Venereology 2013,27:12-29.

7. Bruynzeel I, Bergman W, Hartevelt $\mathrm{H}$, et al. “High single-dose'European PUVA regimen also causes an excess of non-melanoma skin cancer. British journal of dermatology 1991,124:49-55.

8. McKenna K, Patterson C, Handley J, et al. Cutaneous neoplasia following PUVA therapy for psoriasis. British Journal of Dermatology 1996,134:639-642.

9. Lindelöf B, Sigurgeirsson B, Tegner E, et al. PUVA and cancer risk: the Swedish follow-up study. The British journal of dermatology 1999,141:108-112.

10. Margolis D, Bilker W, Hennessy S, et al. The risk of malignancy associated with psoriasis. Archives of dermatology 2001,137:778-783.

11. Stern RS, Liebman EJ, Väkevä L. Oral psoralen and ultraviolet-A light (PUVA) treatment of psoriasis and persistent risk of nonmelanoma skin cancer. JNCI: Journal of the National Cancer Institute 1998,90:1278-1284.

12. Stern R S,Nichols K T,Väkevä L H,Malignant melanoma in patients treated for psoriasis with methoxsalen (psoralen) and ultraviolet A radiation (PUVA). The PUVA Follow-Up Study. N Engl J Med, 1997, 336: 1041-5.

13. Paradisi Andrea, Didona Biagio,Tabolli Stefano et al. Reduced frequency of non-melanoma skin cancer in 72,739 patients with psoriasis: a retrospective study. Eur J Dermatol, 2017, 27: 359-362.

14. Paradisi A, Tabolli S, Didona B, et al. Reduced frequency of melanoma in 72,739 patients with psoriasis: A retrospective study. Eur J Dermatol 2015,25:133-137.

15. Moher D, Liberati A, Tetzlaff J, et al. Preferred reporting items for systematic reviews and meta-analyses: the PRISMA statement. PLoS medicine 2009,6:e1000097

16. Stroup DF, Berlin JA, Morton SC, et al. Meta-analysis of observational studies in epidemiology: a proposal for reporting. Jama 2000,283:2008-2012.

17. Stang A. Critical evaluation of the Newcastle-Ottawa scale for the assessment of the quality of nonrandomized studies in meta-analyses. European journal of epidemiology 2010,25:603-605.

18. DerSimonian R, Laird N. Meta-analysis in clinical trials. Controlled clinical trials 1986,7:177-188

19. Higgins JP, Thompson SG, Deeks JJ, et al. Measuring inconsistency in meta-analyses. Bmj 2003,327:557-560.

20. Egger M, Smith GD, Schneider M, et al. Bias in meta-analysis detected by a simple, graphical test. Bmj 1997,315:629-634

21. Begg CB, Mazumdar M. Operating characteristics of a rank correlation test for publication bias. Biometrics 1994:1088-1101.

22. Duval S, Tweedie R. Trim and fill: a simple funnel-plot-based method of testing and adjusting for publication bias in meta-analysis. Biometrics 2000,56:455-463.

23. Hannuksela-Svahn A, Pukkala E, Läärä E, et al. Psoriasis, its treatment, and cancer in a cohort of Finnish patients. Journal of investigative dermatology 2000,114:587-590.

24. Kimball Alexandra B, Sundaram Murali,Cloutier Martin et al. Increased Prevalence of Cancer in Adult Patients With Psoriasis in the United States: A Claims Based Analysis. J Drugs Dermatol, 2018, 17: 180-186.

25. Asgari MM, Ray GT, Geier JL, et al. Malignancy rates in a large cohort of patients with systemically treated psoriasis in a managed care population. J Am Acad Dermatol 2017,76:632-638.

26. Boffetta P, Gridley G, Lindelof B. Cancer risk in a population-based cohort of patients hospitalized for psoriasis in Sweden. J Invest Dermatol 2001,117:1531-1537.
27. Chen M, Qureshi A, Li T, et al. Personal history of psoriasis and the risk of non-melanoma skin cancers. Journal of Investigative Dermatology 2013,133:S95.

28. Chiesa Fuxench ZC, Shin DB, Ogdie Beatty A, et al. The Risk of Cancer in Patients With Psoriasis: A Population-Based Cohort Study in the Health Improvement Network. JAMA Dermatol 2016,152:282-290.

29. Dai H, Li WQ, Qureshi AA, et al. Personal history of psoriasis and risk of nonmelanoma skin cancer (NMSC) among women in the United States: A population-based cohort study. J Am Acad Dermatol 2016,75:731-735.

30. Egeberg A, Thyssen JP, Gislason GH, et al. Skin cancer in patients with psoriasis. J Eur Acad Dermatol Venereol 2016,30:1349-1353.

31. Frentz G, Olsen J. Malignant tumours and psoriasis: a follow-up study. The British journal of dermatology 1999,140:237-242.

32. Gu Y, Nordstrom BL. The risk of malignancy among biologic-naïve pediatric psoriasis patients: A retrospective cohort study in a US claims database. J Am Acad Dermatol. 2017;77:293-301.e1

33. Ji J, Shu X, Sundquist K, et al. Cancer risk in hospitalised psoriasis patients: a follow-up study in Sweden. Br J Cancer 2009,100:1499-1502.

34. Lee MS, Lin RY, Chang YT, et al. The risk of developing non-melanoma skin cancer, lymphoma and melanoma in patients with psoriasis in Taiwan: a 10-year, population-based cohort study. Int J Dermatol 2012,51:1454-1460.

35. Margolis D, Bilker W, Hennessy S, et al. The risk of malignancy associated with psoriasis. Arch Dermatol 2001,137:778-783.

36. Eklof V, Wikberg ML, Edin S, et al. The prognostic role of KRAS, BRAF, PIK3CA and PTEN in colorectal cancer. Br J Cancer 2013,108:2153-2163.

37. Kang M, Shen XJ, Kim S, et al. Somatic gene mutations in African Americans may predict worse outcomes in colorectal cancer. Cancer Biomark 2013,13:359-366

38. Liao X, Morikawa T, Lochhead P, et al. Prognostic role of PIK3CA mutation in colorectal cancer: cohort study and literature review. Clin Cancer Res 2012,18:2257-2268.

39. Reimers MS, Bastiaannet E, Langley RE, et al. Expression of HLA class I antigen, aspirin use, and survival after a diagnosis of colon cancer. JAMA Intern Med 2014,174:732-739.

40. Rosty C, Young JP, Walsh MD, et al. PIK3CA activating mutation in colorectal carcinoma: associations with molecular features and survival. PLoS One 2013,8:e65479.

41. Fuxench ZCC, Shin DB, Beatty AO, et al. The risk of cancer in patients with psoriasis: a population-based cohort study in the health improvement network. JAMA dermatology 2016,152:282-290

42. Neimann AL, Shin DB, Wang X, et al. Prevalence of cardiovascular risk factors in patients with psoriasis. Journal of the American Academy of Dermatology 2006,55:829-835.

43. Sommer DM, Jenisch S, Suchan M, et al. Increased prevalence of the metabolic syndrome in patients with moderate to severe psoriasis. Archives of dermatological research 2007,298:321.

44. Takeshita J, Grewal S, Langan SM, et al. Psoriasis and comorbid diseases: epidemiology. Journal of the American Academy of Dermatology 2017,76:377-390.

45. Paradisi A, Didona B, Tabolli S, et al. Reduced frequency of non-melanoma skin cancer in 72,739 patients with psoriasis: a retrospective study. European Journal of Dermatology 2017,27:359-362.

46. Shuster S, Chapman PH, Rawlins MD. Psoriasis and cancer. Br Med J 1979,1:941-942.

47. Pouplard C, Brenaut E, Horreau C, et al. Risk of cancer in psoriasis: a systematic review and meta-analysis of epidemiological studies. Journal of the European Academy of Dermatology and Venereology 2013,27:36-46.

48. Peleva E, Exton L S, Kelley K, et al. Risk of cancer in patients with psoriasis on biological therapies: a systematic review. British Journal of Dermatology, 2018, 178(1): 103-113.

49. $\mathrm{Yu} \mathrm{XZ,} \mathrm{Li} \mathrm{J,} \mathrm{Fu} \mathrm{DL} \mathrm{et} \mathrm{al.} \mathrm{Benefit} \mathrm{from} \mathrm{synchronous} \mathrm{portal-superior} \mathrm{mesenteric}$ vein resection during pancreaticoduodenectomy for cancer: a meta-analysis. Eur J Surg Oncol, 2014, 40: 371-378.

50. Lee JW, Jung KJ, Kim TG, et al. Risk of malignancy in patients with psoriasis: a 15-year nationwide population-based prospective cohort study in Korea. J Eur Acad Dermatol Venereol. 2019; in press.

51. Lee Ji Hyun, Kim Hyo Jung, Han Kyung Do et al. Cancer risk in 892089 patients with psoriasis in Korea: A nationwide population-based cohort study. J. Dermatol., 2019, 46: 95-102. 